\title{
Numerical Investigation of Anti-Icing Road Surfaces using Hydronic Heating Pavement- Parametric Study
}

\author{
Raheb Mirzanamadi, Carl-Eric Hagentoft, Pär Johansson \\ Department of Architecture and Civil Engineering, Chalmers University of Technology, \\ Gothenburg, SE-412 96, Sweden \\ Corresponding author E-mail: rahebm@chalmers.se
}

\begin{abstract}
An renewable method to mitigate the slippery condition on road surfaces is to use a Hydronic Heating Pavement (HHP). The performance of the HHP system strongly depends on its design parameters. The aim of this study is to investigate the effects of different design parameters of the HHP system on the anti-icing operation of the road surface. A hybrid 3D numerical simulation model of HHP system is used to make simulation. The numerical model is validated by an analytical solution. The validation result shows that the maximum relative error associated with the temperature decline along the pipe is less than $3 \%$ between the obtained results from the numerical simulation model and the analytical solution. The results show that the order of parameters, investigated in this study, associated with shortening the number of hours of the slippery condition is: (i) the distance between the pipes, (ii) the fluid flow rate, (iii) the inlet temperature of fluid, (iv) the embedded depth of the pipe and (v) the pipe diameter.
\end{abstract}

\section{Introduction}

Winter road maintenance is an essential service to enhance the traffic safety and increase the accessibility of roads during winter time. Distributing sand and salt on the road surface is the most common method to mitigate the slippery condition on the road surface. However, sanding and salting results in pollution of environment and corrosion of road infrastructures (Johnsson, 2017).

A renewable alternative method to increase the level of road safety during winter is to use Hydronic Heating Pavement (HHP). An overall view of the HHP system is shown in Figure 1. For more details the reader is referred to (Mirzanamadi et al., 2018).

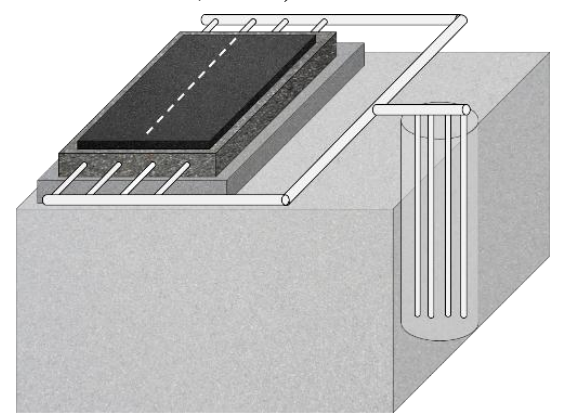

Figure 1. A Overall view of an HHP system

Different numerical models are already developed to simulate the HHP systems. Pahud (2008) made a one- dimensional (1D) numerical model to simulate the hydronic heating system of a bridge. This heating system aimed at keeping the surface temperature above $0^{\circ} \mathrm{C}$ to prevent ice formation and freezing the compacted snow on the bridge (Pahud, 2008). Moreover, Abbasi (2013) developed a 1D numerical model of the hydronic heating system in order to examine two different control systems for heating the road surfaces. The first control system was to keep the road surface temperature above $0^{\circ} \mathrm{C}$ and the second control system was to keep the road surface temperature above the dew-point temperature when the surface temperature is below $0^{\circ} \mathrm{C}$. Their results showed that the annual required energy for heating the road using the second control system is about 10 times less than that using the first control system (Abbasi, 2013).

Although previous studies numerically simulated the HHP system, their main focus were melting the snow on the road surface (Pan et al., 2015). However, the antiicing operation of the HHP system were rarely investigated, especially using a $3 \mathrm{D}$ numerical simulation model. It should be noted that anti-icing, in this study, only refers to the prevention of ice-formation due to deposition of water vapor from the air to the road surface which better known as hoar frost formation (Ou et al., 2018).

The aim of this study is to investigate the effects of different design parameters of the HHP system on the anti-icing operation of the road surface. Five different design parameters are investigated, including (i) the fluid flow rate, (ii) the inlet temperature of fluid, (iii) the pipe diameter, (iv) the distance between the pipes and (v) the embedded depth of the pipe. The anti-icing operation is analysed using a hybrid 3D numerical simulation model of the HHP system. The numerical model is simulated in COMSOL Multiphysics 5.2. and used to calculate: (i) the annual required energy for anti-icing the road surface, (ii) the outlet temperature of the fluid and (iii) the remaining number of hours of the slippery conditions on the road surface.

\section{Hybrid 3D numerical simulation model}

The details related to development of the hybrid 3D numerical simulation model is presented in authors' previous studies (Mirzanamadi, Hagentoft and Johansson, 2018). In this study, the hybrid 3D model is briefly explained and then validated using an analytical solution.

The sketch of a hybrid 3D model of the HHP system is shown in Figure 2. In Figure 2 (a), the HHP system is 
divided to a number of sub-sections. In Figure 2 (b), the $3 \mathrm{D}$ model of the HHP system is represented by $2 \mathrm{D}$ vertical cross sections.

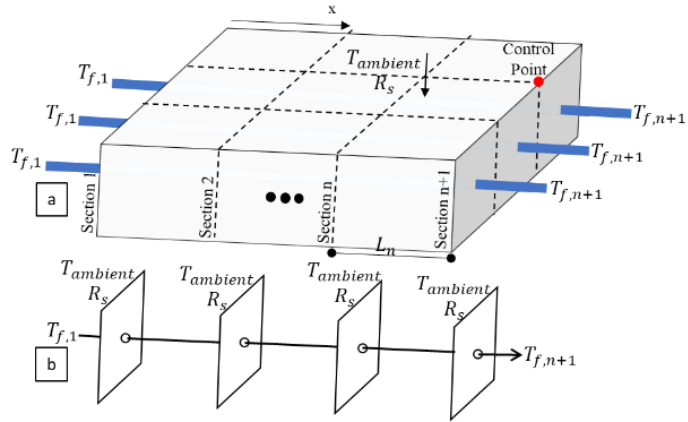

Figure 2. A scheme of the hybrid $3 D$ numerical simulation model (a) the 3D model of a HHP system (b) the hybrid 3D model of the HHP system.

The 2D cross sections are perpendicular to the pipe directions and successively linked to each other by the convective heat transfer in the fluid, circulating inside the pipe. The numerical model simultaneously calculates the transient heat flowing out from the pipes based on the finite element model and the fluid temperature decline along the pipe based on a quasi-steady state assumption.

In each $2 \mathrm{D}$ cross section, the total thermal resistance between the fluid and embedding materials is represented by $R_{\text {eq_pipe }}(\mathrm{m} \cdot \mathrm{K} / \mathrm{W}) \cdot R_{e q}$ consists of three serially coupled thermal resistance, namely: (i) the surface heat transfer resistance at inner pipe surface, $R_{P W S}(\mathrm{~m} \cdot \mathrm{K} / \mathrm{W})$, (ii) the pipe resistance, $R_{p}(\mathrm{~m} \cdot \mathrm{K} / \mathrm{W})$, and (iii) the thermal resistance between the outer pipe wall and an additional annulus surrounding the pipe, $R_{i . j}(\mathrm{~m} \cdot \mathrm{K} / \mathrm{W})$.

$$
\begin{gathered}
R_{\text {eq_pipe }}=R_{\text {pipe }}+R_{i, j}+R_{P W S} \\
R_{\text {pipe }}=\frac{\ln \left(\frac{r_{\text {outer }}}{r_{\text {inner }}}\right)}{2 \cdot \pi \cdot \lambda_{\text {pipe }}} \\
R_{i, j}=\frac{\ln \left(\frac{r_{i, j}}{r_{\text {outer }}}\right)}{2 \cdot \pi \cdot \lambda_{i, j}} \\
R_{P W S}=\frac{1}{\pi \cdot \lambda_{f} \cdot \mathrm{Nu}} \\
\left(\operatorname{Re}=\frac{2 \cdot \rho_{f} \cdot v_{f} \cdot r_{\text {inner }}}{\mu_{f}} \text { and } \operatorname{Pr}=\frac{\mu_{f} \cdot c_{p, f}}{\lambda_{f}}\right)
\end{gathered}
$$

where $\operatorname{Re}(-)$ is the Reynolds number, $\operatorname{Pr}(-)$ is the Prandtl number, $\mathrm{Nu}(-)$ is the Nusselt number, $\rho_{f}\left(\mathrm{~kg} / \mathrm{m}^{3}\right)$ is the density of fluid, $v_{f}(\mathrm{~m} / \mathrm{s})$ is the average velocity of fluid through a cross section of pipe, $r_{\text {inner }}(\mathrm{m})$ and $r_{\text {outer }}(\mathrm{m})$ are respectively the inner and outer radii of the pipe, $r_{i, j}(\mathrm{~m})$ is the radius of the additional annulus surrounding the pipe, $u_{f}(\mathrm{~kg} /(\mathrm{m} \cdot \mathrm{s}))$ is the dynamic viscosity of fluid, $c_{p, f}(\mathrm{~J} /(\mathrm{kg} \cdot \mathrm{K}))$ is the specific heat capacity of fluid, $\lambda_{f}(\mathrm{~W} /(\mathrm{m} \cdot \mathrm{K}))$ is the thermal conductivity of fluid, $\lambda_{\text {pipe }}(\mathrm{W} /(\mathrm{m} \cdot \mathrm{K}))$ is the thermal conductivity of the pipe material and $\lambda_{i, j}(\mathrm{~W} /(\mathrm{m} \cdot \mathrm{K}))$ is the thermal conductivity of the surrounding materials.

If $T_{f}(\mathrm{~K})$ is the temperature of fluid, circulating inside the pipes and $q_{i, j}\left(\mathrm{~W} / \mathrm{m}^{2}\right)$ is the heat flow between the fluid and the surrounding road materials, the equivalent temperature of the road materials close to the pipe segment, $T_{\text {eq_pipe }}(\mathrm{K})$, is calculated as:

$T_{\text {eq_pipe }}=T_{f}-q_{i, j} \cdot R_{\text {eq_pipe }}$

Considering the steady state solution for the longitudinal fluid temperature distribution and the transversal heat transfer process along the pipe, the relation between the inlet and outlet temperatures of the fluid, circulating along the sections $\mathrm{n}$ and $\mathrm{n}+1$, at each time step is obtained as:

$T_{f, n+1}^{t}=T_{\text {eq_pipe, } n}^{t}+\left(T_{f, n}^{t}-T_{\text {eq_pipe, } n}^{t}\right) \cdot e^{-\left(L_{n} / l_{n}\right)}$

where $T_{f, n+1}^{t}(\mathrm{~K})$ is the outlet temperature at time $t$, $T_{f, n}^{t}(\mathrm{~K})$ is the inlet temperature at time $t, L_{n}(\mathrm{~m})$ is the distance between sections $\mathrm{n}$ and $\mathrm{n}+1$ as well as $l_{n}(\mathrm{~m})$ is the characteristic length related to the interaction between the convective heat transfer along the pipe and the transversal heat flow. The value of $l_{n}$ is calculated as:

$$
l_{n}=R_{\text {eq_pipe }} \cdot v_{f} \cdot \pi \cdot r_{\text {inner }}{ }^{2} \cdot \rho_{f} \cdot c_{p, f}
$$

In this study, the inlet temperature of fluid, $T_{f, 1}^{t}(\mathrm{~K})$, is a known parameter. By applying Equations 6 and 7, it is possible to calculate $T_{f, 2}^{t}(\mathrm{~K})$. The value of $T_{f, 2}^{t}$ will be used as the inlet temperature for the second pipe section. By considering the outlet temperature from one section as the inlet temperature for the next section, the outlet temperature for whole length of the pipe will be equal to the outlet temperature at the last pipe section.

In order to validate the hybrid 3D model, the fluid temperature variation along the pipe length for a simple configuration of the HHP system is obtained by an analytical solution and the numerical simulation model. The analytical solution is based on a steady- state study. The HHP system consists of a one-layer road and a single embedded pipe. The pipe is assumed to be located in the middle of an infinite array of pipes (Hagentoft and Roots, 2016). The ambient temperature is set to be $0{ }^{\circ} \mathrm{C}$ and the surface thermal resistance varies from $0\left(\mathrm{~m}^{2} \cdot \mathrm{K}\right) / \mathrm{W}$ to $0.1\left(\mathrm{~m}^{2} \cdot \mathrm{K}\right) / \mathrm{W}$. Other boundaries are set to be adiabatic. It is assumed that the road and pipe materials are homogenous. The analytical solution accounts for the distance between the pipes, the embedded depth of the pipes, the pipe diameter, the thermal conductivity of road and pipe materials, the surface thermal resistance, the length of the pipes, the fluid flow rate and the fluid properties (density and specific heat capacity). The length of pipe is set to be $L(\mathrm{~m})$. The inlet temperature of fluid is $T_{\text {in }}(\mathrm{K})$ and the outlet temperature is $T_{\text {out }}(\mathrm{K})$. Equations 8-13 are used in the analytical solution (Hagentoft and Roots, 2016).

$$
\begin{gathered}
R_{0}=\frac{1}{2 \pi \lambda}\left(\ln \left(\frac{2 D}{r_{\text {pipe }}}\right)+\ln \left(\frac{c}{2 \pi D} \cdot \sinh \left(\frac{2 \pi D}{c}\right)\right)+4 \cdot \sum_{n=1}^{\infty} e^{v}\right. \\
E_{1}(v)+2 \cdot e^{\left.\frac{2 D}{d} \cdot E_{1}\left(\frac{2 D}{d}\right)\right)} \\
d=R_{s} \cdot \lambda \\
E_{1}(v)=\int_{v}^{\infty} \frac{e^{-x}}{x} d x \\
v=\frac{2 D+i \cdot n c}{d} \\
T_{\text {out }}=T_{S}+\left(T_{\text {in }}-T_{s}\right) \cdot e^{-\frac{L}{l}}
\end{gathered}
$$




$$
l=R_{0} \cdot v_{f} \cdot \pi \cdot r_{\text {inner }}{ }^{2} \cdot \rho_{f} \cdot c_{p, f}
$$

where $R_{0}(\mathrm{~m} \cdot \mathrm{K} / \mathrm{W})$ is the thermal resistance between the pipes and the surface, $\lambda(\mathrm{W} /(\mathrm{m} \cdot \mathrm{K}))$ is the thermal conductivity of road materials, $D(\mathrm{~m})$ is the depth of embedded pipe from centre to surface, $c(\mathrm{~m})$ is the distance between pipes, $r_{\text {pipe }}(\mathrm{m})$ is the radius of the pipe and $R_{S}\left(\mathrm{~m}^{2} \cdot \mathrm{K} / \mathrm{W}\right)$ is the surface thermal resistance.

The analytical solution is based on a semi-infinite geometry. The depth of the numerical simulation model was truncated to 10 times the embedded depth of the pipe, from the pipe centre to the surface. Furthermore, the numerical simulation model consists of four crosssections. The geometrical information and the thermal properties of the road section are presented in Table 1.

The results associated with the fluid temperature variation along the pipe length are shown in Figure 3. As can be seen, the results related to the analytical solution and the numerical simulation are matching well with each other, so the maximum relative error is $2.3 \%$ which is related to the case that $R_{s}=0\left(\mathrm{~m}^{2} \cdot \mathrm{K}\right) / \mathrm{W}$. The maximum relative error is defined as the difference between the results of analytical solutions and numerical model divided to the results of the analytical solution. By increasing the surface thermal resistance, the maximum relative error will decrease; e.g., for $R_{s}=0.1\left(\mathrm{~m}^{2} \cdot \mathrm{K}\right) / \mathrm{W}$ the maximum relative error is $2 \%$. It should be noted that an increase in the number of cross-sections will lead to a decrease in the maximum relative error. For example, for the numerical model with eight cross-sections the maximum relative error is $1.4 \%$ and for the numerical model with 11 crosssections the maximum relative error is $0.06 \%$.

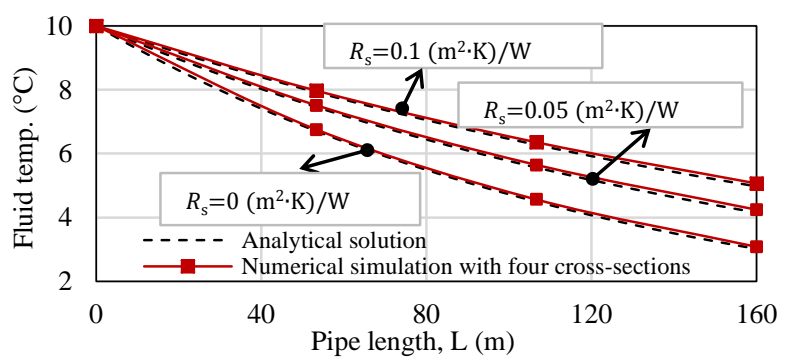

Figure 3. Fluid temperature variation along the pipe length considering different surface thermal resistances.

\section{Heat balance}

In this study, the aim of anti-icing is to prevent the hoar frost formation. The heating system is not used for snow melting and ice-formation due to rain. Hence, the mass balance of the water on the road surface is assumed to be only based on condensation and evaporation. To simply the numerical model, it is assumed that all snowfalls are immediately ploughed away from the road surfaces and the rainfall is drained well. the heat flux associated with the latent heat of the snow melting is not taken into account due to snow removal. However, falling snow, before the snow removal is started, affects the heat balance of the road surface. Hence, the sensible heat flux of snow, $q_{\text {snow }}\left(\mathrm{W} / \mathrm{m}^{2}\right)$, related to the heat capacity of snow and temperature change is considered in the heat balance. the heat balance on the road surface consists of seven heat fluxes as Equations 15-21. The equations are extracted from (Hagentoft, 2001). For more details about the heat balance, the reader is referred to (Mirzanamadi et al., 2018).

The heat balance is calculated as:

$$
\begin{aligned}
& q_{\text {cond }}+q_{\text {conv }}+q_{\text {rain }}+q_{\text {snow }}+q_{l w}+q_{s w}+ \\
& q_{\text {evp } / \text { con }}=0
\end{aligned}
$$

- conductive heat from ground and pipes:

$$
q_{\text {cond }}=-\lambda \cdot \nabla T
$$

- convective heat flow from the ambient air

$$
q_{\text {conv }}=h_{c} \cdot\left(T_{\text {ambient }}-T_{\text {surface }}\right)
$$

- $\quad$ sensible heat from rain

$q_{\text {rain }}=\dot{m}_{\text {rain }} \cdot c_{\text {p-water }} \cdot\left(T_{\text {ambient }}-T_{\text {surface }}\right)(17)$

- $\quad$ sensible heat from snow

$q_{\text {snow }}=\dot{m}_{\text {snow }} \cdot c_{\text {p-snow }} \cdot\left(T_{\text {ambient }}-T_{\text {surface }}\right)(18)$

- long-wave radiation

$$
q_{l w}=\varepsilon \cdot \sigma \cdot\left(T_{\text {sky }}^{4}-T_{\text {surface }}^{4}\right)
$$

- $\quad$ short-wave radiation

$$
q_{s w}=\alpha \cdot I
$$

- latent heat of evaporation and condensation

$$
q_{\text {evp } / \text { con }}=h_{e} \cdot \beta \cdot\left(v_{\text {ambient }}-v_{s}\right)
$$

where $\lambda(\mathrm{W} /(\mathrm{m} \cdot \mathrm{K}))$ is the thermal conductivity of the road materials, $T(\mathrm{~K})$ is the temperature, $T_{\text {ambient }}(\mathrm{K})$ is the ambient air temperature, $T_{\text {surface }}(\mathrm{K})$ is the road surface temperature, $h_{c}\left(\mathrm{~W} /\left(\mathrm{m}^{2} \cdot \mathrm{K}\right)\right)$ is the convective heat transfer coefficient, $\varepsilon(-)$ is the emissivity of the surface, $\sigma\left(\mathrm{W} /\left(\mathrm{m}^{2} \cdot \mathrm{K}^{4}\right)\right)$ is the Stefan-Boltzmann constant, $T_{\text {sky }}(\mathrm{K})$ is the sky temperature, $\alpha(-)$ is the solar absorptivity of the surface, $I\left(\mathrm{~W} / \mathrm{m}^{2}\right)$ is the solar irradiation, $h_{e}(\mathrm{~J} / \mathrm{kg})$ is the latent heat of evaporation of water, $\beta(\mathrm{m} / \mathrm{s})$ is the moisture transfer coefficient, $v_{\text {ambient }}\left(\mathrm{kg} / \mathrm{m}^{3}\right)$ is the humidity by the volume of the ambient air, $v_{S}\left(\mathrm{~kg} / \mathrm{m}^{3}\right)$ is the humidity by the volume of the saturated air at the surface temperature and $\dot{m}(\mathrm{~kg} /$ $\left.\left(\mathrm{m}^{2} \cdot \mathrm{s}\right)\right)$ is the mass rate of snow/rain per square meter of the surface.

Table 1. Input data of the initial simulated HHP for validation (Fluid is $25 \%$ ethylene glycol-water mixture).

\begin{tabular}{|l|c|c|l|c|c|}
\hline Parameter & Value & Unit & Parameter & Unit \\
\hline Surface thermal resistance & $0-0.05-0.1$ & $\left(\mathrm{~m}^{2} \cdot \mathrm{K}\right) / \mathrm{W}$ & Diameter of additional annulus $\left(2 \cdot \mathrm{r}_{\mathrm{i}, \mathrm{j}}\right)$ & 160 & $\mathrm{~mm}$ \\
\hline Ambient temperature & 0 & ${ }^{\circ} \mathrm{C}$ & Fluid inlet temperature & 10 & ${ }^{\circ} \mathrm{C}$ \\
\hline Distance between two pipes & 400 & $\mathrm{~mm}$ & Pipe length & 160 & $\mathrm{~m}$ \\
\hline Thermal conductivity of road material & 1.5 & $\mathrm{~W} /(\mathrm{m} \cdot \mathrm{K})$ & Fluid flow rate & 5.65 & $1 / \mathrm{min}$ \\
\hline Density of road material & 2400 & $\mathrm{~kg} / \mathrm{m}^{3}$ & Thermal conductivity of fluid & 0.488 & $\mathrm{~W} /(\mathrm{m} \cdot \mathrm{K})$ \\
\hline Specific heat capacity of road material & 850 & $\mathrm{~J} /(\mathrm{kg} \cdot \mathrm{K})$ & Specific heat capacity of fluid & 3852 & $\mathrm{~J} /(\mathrm{kg} \cdot \mathrm{K})$ \\
\hline Embedded depth & 100 & $\mathrm{~mm}$ & Density of fluid & 1025 & $\mathrm{~kg} / \mathrm{m}^{3}$ \\
\hline Pipe diameter & 20 & $\mathrm{~mm}$ & Number of section & - & - \\
\hline
\end{tabular}




\section{Boundary condition}

The climate data were obtained from Östersund, a city in middle of Sweden. The city has long and cold winter period which is interesting to simulate the anti-icing operation. The climate data were generated at a 1 hour interval (Meteotest, 2010) and included: dry-bulb/air temperature $\left({ }^{\circ} \mathrm{C}\right)$, relative humidity $(\%)$, wind speed $(\mathrm{m} / \mathrm{s})$, dew-point temperature $\left({ }^{\circ} \mathrm{C}\right)$, incoming long-wave radiation $\left(\mathrm{W} / \mathrm{m}^{2}\right)$, short-wave radiation $\left(\mathrm{W} / \mathrm{m}^{2}\right)$ and precipitation $(\mathrm{mm} / \mathrm{h})$.

In the numerical simulation model, the temperature of ground at the depth of $5 \mathrm{~m}$ is set to be $2.53^{\circ} \mathrm{C}$, equal to the annual mean temperature of ambient air. The road structure consists of six different layers. The details of the layers are presented in Table 2.

Table 2. Materials properties of the road layers.

\begin{tabular}{|l|c|c|c|c|}
\hline $\begin{array}{l}\text { Road } \\
\text { layer }\end{array}$ & $\begin{array}{c}\text { Thick- } \\
\text { ness } \\
(\mathbf{m m})\end{array}$ & $\begin{array}{c}\text { Thermal } \\
\text { Conductivity } \\
(\mathbf{W} /(\mathbf{m} \cdot \mathbf{K}))\end{array}$ & $\begin{array}{c}\text { Density } \\
\left(\mathbf{k g} / \mathbf{m}^{3}\right)\end{array}$ & $\begin{array}{c}\text { Specific Heat } \\
\text { Capacity } \\
(\mathbf{J} /(\mathbf{k g} \cdot \mathbf{K}))\end{array}$ \\
\hline Wearing & 40 & 2.24 & 2415 & 848 \\
\hline Binder & 60 & 1.44 & 2577 & 822 \\
\hline Base & 100 & 1.51 & 2582 & 894 \\
\hline Subbase & 80 & 0.7 & 1700 & 900 \\
\hline Subgrade & 1000 & 0.8 & 1400 & 900 \\
\hline Ground & 3720 & 0.6 & 1300 & 600 \\
\hline
\end{tabular}

The geometrical and thermal properties of the road and pipe materials as well as the thermal properties of the fluid are presented in Table 3. The data associated with the pipe material, made from polyethylene (PEX), are obtained from (Modin, 2015) and the data associated with the thermal properties of fluid, $25 \%$ ethylene glycol-water mixture, are obtained from (Bohne, Fischer and Obermeier, 1984).

Let's assume $T_{\text {surface }}(\mathrm{K})$ is the surface temperature, $T_{\text {dew }}(\mathrm{K})$ is the dew-point temperature and $T_{\text {freezing }}(\mathrm{K})$ is the freezing temperature of water. When $T_{\text {surface }}<$ $T_{\text {dew }}$, the water will be formed on the road surface due to the condensation. When $T_{\text {surface }}<T_{\text {freezing }}$, the water on the road surface will turn to ice. Therefore, in order to avoid the occurrence of the condensation on the road surface, the heating system should turn on when:

$$
\left\{\begin{array}{l}
T_{\text {surface }}<T_{\text {dew }} \\
T_{\text {surface }}<T_{\text {freezing }}
\end{array}\right.
$$

The heat conduction from the pipes to the surface does not distribute uniformly on the road surface. The points on the surface directly above the heating pipe will have the maximum temperature and the shortest number of hours of the slippery conditions. Furthermore, considering the fluid temperature decline along the pipe, the points on the road surface which are located in the middle between two pipes at the outlet section will have the minimum surface temperature and the longest number of hours of the slippery conditions (See "Control Point" in Figure 2).

Whenever the heating system is turned on, the temperature of fluid is set to be $12{ }^{\circ} \mathrm{C}$. Whenever the heating system is turned off, the boundary condition at the inner surface of the pipe wall is set to be adiabatic. The annual required energy for anti-icing the road surface using the temperature difference between the inlet and outlet fluids, $E_{r}\left(\mathrm{kWh} /\left(\mathrm{m}^{2} \cdot\right.\right.$ year $\left.)\right)$, is calculated as:

$E_{r}=\frac{1}{c \cdot L} \cdot \int_{t=0}^{1 \text { year }}\left(T_{f, \text { out }}^{t}-T_{f, \text { in }}^{t}\right) \cdot v_{f} \cdot \pi \cdot r_{\text {inner }}{ }^{2} \cdot \rho_{f} \cdot c_{p, f} \cdot d t$

where $c(\mathrm{~m})$ is the distance between pipes and $L(\mathrm{~m})$ is the pipe length.

Furthermore, the number of hours of the slippery condition on the road surface, $t_{\text {slippery }}(\mathrm{h})$, are the number of hours when the temperature of the road surface is lower than both freezing and dew-point temperatures. The value of $t_{\text {slippery }}$ is calculated as:

$t_{\text {slippery }}=\int_{0}^{1 \text { year }} f \cdot d t\left(f=1\right.$ if $\left(\begin{array}{c}T_{\text {surface }}<T_{\text {dew }} \\ T_{\text {surface }}<T_{\text {freezing }}\end{array}\right)$ else $\left.f=0\right)$

It should be noted that in the above equation, $T_{\text {surface }}$ is the surface temperature at "Control Point", see Figure 2.

\section{Results and discussion}

This section presents the effects of (i) the number of vertical sections and (ii) the parametric study of the HHP system on the anti-icing operation of the HHP system.

\section{Number of vertical cross-sections}

Table 4 presents the results related to the anti-icing operation by varying the number of cross-sections from 2 to 6 . As can be seen, where the number of cross sections is equal to or more than $3, t_{\text {slippery }}$ is approximately 137 $\mathrm{h}$ and the outlet temperature is $5.6^{\circ} \mathrm{C}$. For the numerical model with four and more cross-sections, the annual required energy for anti-icing is about $91 \mathrm{kWh} /\left(\mathrm{m}^{2} \cdot\right.$ year $)$. Selecting the number of cross sections is influenced by the characteristic length, $l_{n}(\mathrm{~m})$. As the value of $l_{n}$ is higher, the accuracy of the results gets better. Furthermore, the value of $l_{n}$ is influenced by the total thermal resistance between the fluid and the embedded materials, $R_{e q}(\mathrm{~m} \cdot \mathrm{K} / \mathrm{W})$. By increasing the value of $R_{e q}$, the value of $l_{n}$ and consequently the accuracy of results will increase.

\begin{tabular}{|c|c|c|c|c|c|}
\hline Parameter & Value & Unit & Parameter & Value & Unit \\
\hline Thermal conductivity of pipe materials & 0.4 & $\mathrm{~W} /(\mathrm{m} \cdot \mathrm{K})$ & Absorptivity of the road surface & 0.78 & - \\
\hline Density of pipe materials & 925 & $\mathrm{~kg} / \mathrm{m}^{3}$ & Fluid inlet temperature & 12 & ${ }^{\circ} \mathrm{C}$ \\
\hline Specific heat capacity of pipe materials & 2300 & $\mathrm{~J} /(\mathrm{kg} \cdot \mathrm{K})$ & Pipe length & 50 & $\mathrm{~m}$ \\
\hline Outer diameter of the embedded pipes & 25 & $\mathrm{~mm}$ & Fluid flow rate & 8 & $1 / \mathrm{min}$ \\
\hline Inner diameter of the embedded pipes & 20.4 & $\mathrm{~mm}$ & Thermal conductivity of fluid & 0.488 & $\mathrm{~W} /(\mathrm{m} \cdot \mathrm{K})$ \\
\hline Diameter of additional annulus $\left(2 \cdot r_{\mathrm{i}, \mathrm{j}}\right)$ & 30.4 & $\mathrm{~mm}$ & Specific heat capacity of fluid & 3852 & $\mathrm{~J} /(\mathrm{kg} \cdot \mathrm{K})$ \\
\hline Distance between the pipes (center to center) & 100 & $\mathrm{~mm}$ & Density of fluid & 1025 & $\mathrm{~kg} / \mathrm{m}^{3}$ \\
\hline Embedded depth from center of pipe to surface & 87.5 & $\mathrm{~mm}$ & Dynamic viscosity & 2.9 & $\mathrm{mPa} \cdot \mathrm{s}$ \\
\hline Emissivity of the road surface & 0.89 & - & & & \\
\hline
\end{tabular}

Table 3. Input data of the initial simulated HHP system in this study (Fluid is 25\% ethylene glycol-water mixture). 
Table 4. Effects of numbers of cross sections.

\begin{tabular}{|c|c|c|c|}
\hline $\begin{array}{c}\text { Number } \\
\text { of cross- } \\
\text { sections }\end{array}$ & $\begin{array}{c}\text { Remaining } \\
\text { slippery hours, } \\
\boldsymbol{t}_{\text {slippery }}(\mathbf{h})\end{array}$ & $\begin{array}{c}\text { Annual required } \\
\text { energy along the pipe, } \\
\boldsymbol{E}_{\boldsymbol{r}}\left(\mathbf{k W h} /\left(\mathbf{m}^{\mathbf{2}} \cdot \mathbf{y e a r}\right)\right)\end{array}$ & $\begin{array}{c}\text { Average } \\
\text { out-let } \\
\text { Temp. }\left({ }^{\circ} \mathbf{C}\right)\end{array}$ \\
\hline 2 & 134.7 & 86.8 & \multirow{2}{*}{5.8} \\
\hline 3 & 136.8 & 89.9 & \multirow{2}{*}{5.6} \\
\hline 5 & 136.5 & 90.5 & \\
\hline 6 & 137.1 & 90.8 & \\
\hline
\end{tabular}

It should be noted that having fewer number of crosssections causes the computational time to decrease, e.g. in this study, the computational time for solving the numerical simulation model using four cross-sections was $54.3 \mathrm{~min}$, while this time was $112.9 \mathrm{~min}$ for the model with five cross-sections. The numerical simulation model was run in a computer with 16 GB RAM and a processor of Intel (R) Core (TM) i7-4600K CPU @ 2.1 GHz.

\section{Parametric study}

The relative difference between the results related to the numerical simulation model with four and more crosssections in Table 4 is less than $1 \%$. To reduce the computational time, the hybrid 3D numerical simulation model with four cross sections is selected to accomplish the parametric study. Five different parameters including (i) fluid flow rate, (ii) fluid temperature, (iii) pipe diameter, (iv) distance between the pipes and (v) embedded depth of the pipes are examined to find out their influence on the anti-icing operation. It is assumed that by varying one parameter, the values of other parameters will remain the same as Table 3.

\section{Fluid flow rate}

From the literature (Dehdezi, 2012), the fluid flow rate is varied from $1 \mathrm{l} / \mathrm{min}$ to $180 \mathrm{l} / \mathrm{min}$. However, to avoid noise pollution and pipe damaging the fluid flow velocity should not exceed $2.5 \mathrm{~m} / \mathrm{s}$ (The Engineering ToolBox, 2001). Considering the inner pipe diameter of $20.4 \mathrm{~mm}$, see Table 3, the maximum fluid flow rate will be $50 \mathrm{l} / \mathrm{min}$. The annual required energy, the average outlet temperatures of fluid, the thermal resistance of fluid and pipe and the remaining number of hours of the slippery conditions are shown in Figure 4.

As shown in Figure 4 (a), the variation of annual required energy for anti-icing, $E_{r}\left(\mathrm{kWh} /\left(\mathrm{m}^{2} \cdot\right.\right.$ year $\left.)\right)$, versus the fluid flow rate, $\dot{V}_{f}(1 / \mathrm{min})$ consists of three segments: (i) an initial steep decrease in $E_{r}$ where $\dot{V}_{f}<8 \mathrm{l} / \mathrm{min}$, (ii) an abrupt spike in $E_{r, 1}$ where $\dot{V}_{f}$ is around $81 / \mathrm{min}$ and (ii) and a gradual decrease in $E_{r}$ where $\dot{V}_{f} \geq 8 \mathrm{l} / \mathrm{min}$. However, Figure 4 (b) exhibits a reverse trend for the variation of outlet temperature of fluid, $T_{\text {out }}\left({ }^{\circ} \mathrm{C}\right)$ versus $\dot{V}_{f}$. The
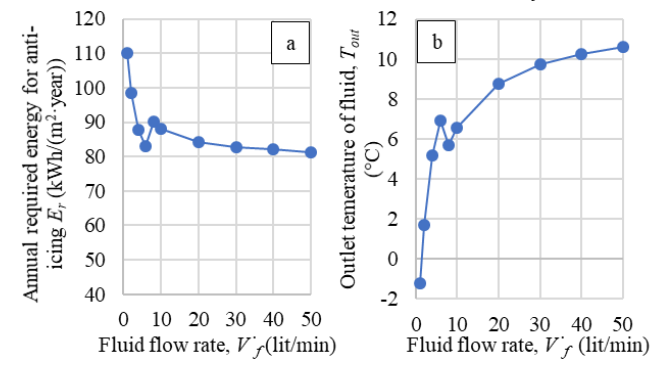

variation of $E_{r}$ and $T_{\text {out }}$ is influenced by the variation of Reynolds number, Re. From Equations 4, for $\dot{V}_{f}=$ $6 \mathrm{l} / \mathrm{min}, \operatorname{Re}(-)$ is 2206 and for $\dot{V}_{f}=8 \mathrm{l} / \mathrm{min}, \operatorname{Re}$ is 2941. The value of Re affects the surface heat transfer resistance at inner pipe surface, $R_{P W S}(\mathrm{~m} \cdot \mathrm{K} / \mathrm{W})$. As can be seen in Figure 4 (c), where $\dot{V}_{f}$ is around $81 / \mathrm{min}$, the value of $R_{P W S}$ promptly decreases from $0.16 \mathrm{~m} \cdot \mathrm{K} / \mathrm{W}$ to $0.016 \mathrm{~m} \cdot \mathrm{K} / \mathrm{W}$. The thermal resistances of the pipe, $R_{p}(\mathrm{~m} \cdot \mathrm{K} / \mathrm{W})$ and the additional annulus, $R_{i, j}(\mathrm{~m} \cdot \mathrm{K} / \mathrm{W})$ are constant for whole range of $\dot{V}_{f}$; i.e. $R_{p}+R_{i, j}=0.1 \mathrm{~m} \cdot \mathrm{K} / \mathrm{W}$. Consequently, the total thermal resistance, $R_{e q}(\mathrm{~m} \cdot \mathrm{K} / \mathrm{W})$ promptly decreases from $0.27 \mathrm{~m} \cdot \mathrm{K} / \mathrm{W}$ to $0.12 \mathrm{~m} \cdot \mathrm{K} / \mathrm{W}$ where $\dot{V}_{f}$ is around $8 \mathrm{l} / \mathrm{min}$. Furthermore, Figure 4 (d) shows that the remaining number of hours of the slippery conditions on the road surface, $t_{\text {slippery }}(\mathrm{h})$, reduces significantly from $633 \mathrm{~h}$ to $135 \mathrm{~h}$ where $\dot{V}_{f}$ ranges from $1 \mathrm{l} / \mathrm{min}$ to $8 \mathrm{l} / \mathrm{min}$. For $\dot{V}_{f} \geq 8 \mathrm{l} / \mathrm{min}$, the value of $t_{\text {slippery }}$ reaches to a gradual depression trend, so reduces down from $135 \mathrm{~h}$ to $87 \mathrm{~h}$ where the $\dot{V}_{f}$ varies between $8 \mathrm{l} / \mathrm{min}$ to $50 \mathrm{l} / \mathrm{min}$.

\section{Fluid temperature}

From the literature (Bobes-Jesus et al., 2013; Pan et al., 2015), the fluid temperature varied at a range between $25^{\circ} \mathrm{C}$ and $50^{\circ} \mathrm{C}$. This range of temperature was used to snow melting, however, is high for anti-icing the road surface. The aim of anti-icing is to keep the $T_{\text {surface }}$ higher than (but close to) $T_{\text {dew }}$ when $T_{\text {surface }}<T_{\text {freezing }}$, see Section 4. In order to examine if this aim is satisfied using a lower fluid temperature than $25^{\circ} \mathrm{C}$, seven fluid temperatures of $4{ }^{\circ} \mathrm{C}, 6^{\circ} \mathrm{C}, 8^{\circ} \mathrm{C}, 10{ }^{\circ} \mathrm{C}, 12^{\circ} \mathrm{C}, 16^{\circ} \mathrm{C}$ and $20^{\circ} \mathrm{C}$ are arbitrary taken into account.

The results related to the annual required energy, the average outlet temperature and the remaining number of hours of the slippery conditions are shown in Figure 5.

As shown in Figure 5 (a), by increasing the inlet temperature of fluid, $T_{\text {in }}\left({ }^{\circ} \mathrm{C}\right)$, from $4{ }^{\circ} \mathrm{C}$ to $20{ }^{\circ} \mathrm{C}$, the value of $E_{r}$ increases from $81.2 \mathrm{kWh} /\left(\mathrm{m}^{2}\right.$.year $)$ to 96.9 $\mathrm{kWh} /\left(\mathrm{m}^{2} \cdot\right.$ year $)$. Higher $T_{\text {in }}$ causes higher surface temperature and consequently results in more energy consumption. Figure 5 (b) illustrates the variation of average outlet temperature, $T_{\text {out }}$, versus $T_{i n}$. As can be seen, by increasing $T_{i n}$, the difference between $T_{i n}$ and $T_{\text {out }}$ will increase. Furthermore, an increase in $T_{\text {in }}$ results in an increase in $T_{\text {out }}$. Circulating a higher fluid temperature along the pipe will lead to a decrease in the number of hours of the slippery conditions on the road surface, $t_{\text {slippery }}$.
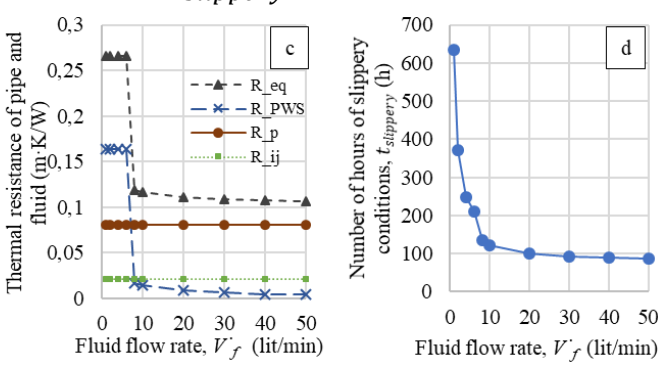

Figure 4. The effects of fluid flow rate on anti-icing operation (a) the annual required energy, (b) the average outlet temperature of fluid, $(c)$ the thermal resistances $(d)$ the remaining number of hours of the slippery conditions. 
From Figure 5 (c), by increasing $T_{\text {in }}$ from $4{ }^{\circ} \mathrm{C}$ to $20{ }^{\circ} \mathrm{C}$, the value of $t_{\text {slippery }}$ reduces from $284 \mathrm{~h}$ to $93 \mathrm{~h}$. The decrease of $t_{\text {slippery }}$ follows a convex curve; i.e. as the value of $T_{\text {in }}$ increases the number of slippery hours approximates to the preceding value of $t_{\text {slippery }}$.
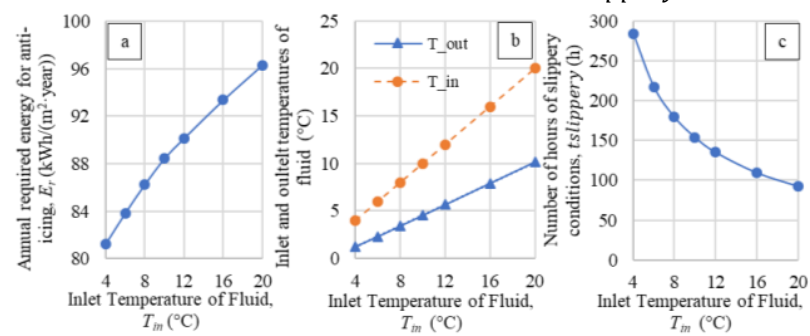

Figure 5. The effects of fluid temperature on anti-icing operation (a) the annual required energy, $(b)$ the average outlet temperature of fluid and (c) the remaining number of hours of the slippery conditions

\section{Outer diameter of pipe}

From the literature (Bobes-Jesus et al., 2013; Pan et al., 2015), the diameter of pipes, installed in the HHP system, varies from $6 \mathrm{~mm}$ to $50 \mathrm{~mm}$. In this study, five different outer diameters are taken into account, including: $13 \mathrm{~mm}$, $20 \mathrm{~mm}, 25 \mathrm{~mm}, 30 \mathrm{~mm}$ and $40 \mathrm{~mm}$. In addition, it is assumed that: (i) the thickness of all pipe is $2.3 \mathrm{~mm}$, (ii) the diameter of the additional annulus is $10 \mathrm{~mm}$ larger than the outer diameter of pipe, (iii), the embedded depth from the centre of pipe to the surface is $87.5 \mathrm{~mm}$ and (iv) the fluid flow rate for all different pipe diameters is 8 $1 / \mathrm{min}$. It is worth mentioning that for the smaller diameters than $13 \mathrm{~mm}$, the flow velocity of fluid exceeds $2.5 \mathrm{~m} / \mathrm{s}$, which is not recommended (The Engineering ToolBox, 2001). The annual required energy, the average outlet temperatures of fluid, the thermal resistance of fluid and pipe and the remaining number of hours of the slippery conditions are shown in Figure 6.

In Figure 6 (a), the value of $E_{r}$ initially increases from $81.1 \mathrm{kWh} /\left(\mathrm{m}^{2} \cdot\right.$ year $)$ to $92.6 \mathrm{kWh} /\left(\mathrm{m}^{2} \cdot\right.$ year $)$ where the outer diameter of pipe, $D I A_{\text {out }}(\mathrm{mm})$, varies from $13 \mathrm{~mm}$ to $30 \mathrm{~mm}$. However, the value of $E_{r}$ shows a depression trend from $92.6 \mathrm{kWh} /\left(\mathrm{m}^{2} \cdot\right.$ year $)$ to $84.8 \mathrm{kWh} /\left(\mathrm{m}^{2} \cdot\right.$ year $)$ where $D I A_{\text {out }}$ varies from $30 \mathrm{~mm}$ to $40 \mathrm{~mm}$. A reverse trend is illustrated for the variation of $T_{\text {out }}$ versus $D I A_{\text {out }}$ in Figure 6 (b). The value of $T_{\text {out }}$ decreases from $7.9^{\circ} \mathrm{C}$ to $4.9^{\circ} \mathrm{C}$ where $D I A_{\text {out }}$ ranges between $13 \mathrm{~mm}$ and $30 \mathrm{~mm}$, then increases to $7.25^{\circ} \mathrm{C}$ where $D I A_{\text {out }}$ is $40 \mathrm{~mm}$. The variation of $E_{r}$ and $T_{\text {out }}$ is related to the variation of $\mathrm{Re}$

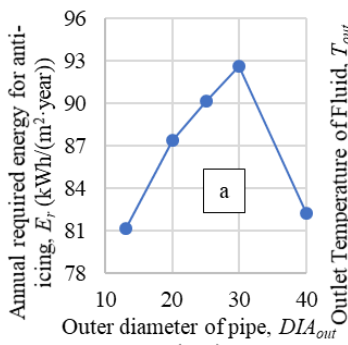

$(\mathrm{mm})$

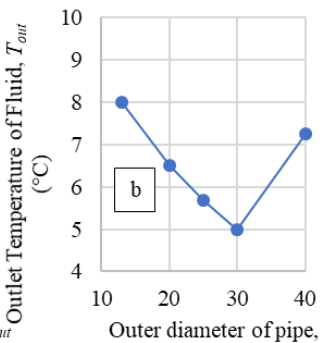

$D I A_{\text {out }}(\mathrm{mm})$

versus $D I A_{\text {out }}$. For $D I A_{\text {out }}=30 \mathrm{~mm}$, the value of $\mathrm{Re}$ is 2362 and for $D I A_{\text {out }}=40 \mathrm{~mm}$, the value of Re is 1695 .

As shown in Figure 6 (c), for $D I A_{\text {out }} \leq 30 \mathrm{~mm}, R_{P W S}$ ranges between $0.008 \mathrm{~m} \cdot \mathrm{K} / \mathrm{W}$ and $0.02 \mathrm{~m} \cdot \mathrm{K} / \mathrm{W}$, while for $D I A_{\text {out }}>30 \mathrm{~mm}$, the value of $R_{P W S}$ jumps to 0.16 $\mathrm{m} \cdot \mathrm{K} / \mathrm{W}$. This jump causes an increase in the value of $R_{e q}$ which in turn results in a decline in the conductive heat transfer between the pipe and road surface, $q_{\text {cond }}\left(\mathrm{W} / \mathrm{m}^{2}\right)$. As the value of $q_{\text {cond }}$ decreases, the remaining risk for the slippery condition on the road surface will increase, see Figure $6(\mathrm{~d})$ when $D I A_{\text {out }}>30 \mathrm{~mm}$.

\section{Distance between pipes}

This section presents the effects of the distance between the pipes on the anti-icing operation of the HHP system. The minimum distance is considered to be $50 \mathrm{~mm}$ (center to center). This value is twice the outer diameter of the pipe. The closer distance might result in segregation of aggregate of asphalt concrete. Moreover, the maximum distance is considered to be $400 \mathrm{~mm}$ (Bobes-Jesus et al., 2013; Pan et al., 2015). Six difference distances between these two ranges are arbitrary selected. The distances are: $50 \mathrm{~mm}, 100 \mathrm{~mm}, 150 \mathrm{~mm}, 200 \mathrm{~mm}, 300 \mathrm{~mm}$ and $400 \mathrm{~mm}$. The annual required energy, the average outlet temperature and the remaining number of hours of the slippery conditions on the surface are shown in Figure 7.

As can be seen in Figure 7 (a), by increasing the distance between pipes, $c(\mathrm{~mm})$, the value of $E_{r}$ initially declines from $97.8 \mathrm{kWh} /\left(\mathrm{m}^{2} \cdot\right.$ year $)$ to $87.8 \mathrm{kWh} /\left(\mathrm{m}^{2} \cdot\right.$ year $)$ where $50 \mathrm{~mm} \leq c \leq 200 \mathrm{~mm}$. However, for $200 \mathrm{~mm} \leq c \leq 400$ $\mathrm{mm}$, the value of $E_{r}$ shows an increase from 87.8 $\mathrm{kWh} /\left(\mathrm{m}^{2} \cdot\right.$ year $)$ to $92.9 \mathrm{kWh} /\left(\mathrm{m}^{2} \cdot\right.$ year $)$. It should be noted that, multiplying $E_{r}$ by $c$ will result in the annual required energy related to a single pipe, $E_{r} \cdot c(\mathrm{kWh} /(\mathrm{m} \cdot$ year $))$. The value of $E_{r} \cdot c$ follows a rising trend by increasing the value of $c$. The same trend is illustrated for $T_{\text {out }}$ in Figure 7 (b). As shown, where the value of $c$ is at the range of 50 $\mathrm{mm}$ to $400 \mathrm{~mm}$, the value of $T_{\text {out }}$ increases from $5.6^{\circ} \mathrm{C}$ to $7.6{ }^{\circ} \mathrm{C}$, resulting in the reduction of temperature difference between $T_{\text {in }}$ and $T_{\text {out }}\left(T_{\text {in }}=12^{\circ} \mathrm{C}\right)$. As the value of $c$ increases, the surface temperature decreases and consequently the risk of the slippery conditions on the road surface will increase. Figure 7 (c) shows that the value of $t_{\text {slippery }}$ significantly increases from $71 \mathrm{~h}$ to 795 $\mathrm{h}$ by varying the value of $c$ from $50 \mathrm{~mm}$ to $400 \mathrm{~mm}$. The curve associated with $t_{\text {slippery }}$ versus $c$ follows a convex function; i.e. the increase in the value of $t_{\text {slippery }}$ gets greater as the value of $c$ increases.

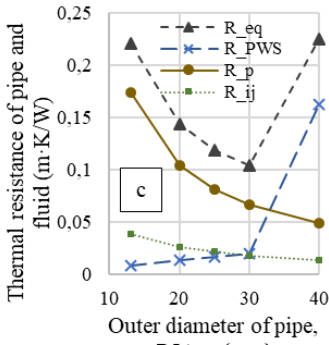

$D I A_{\text {out }}(\mathrm{mm})$

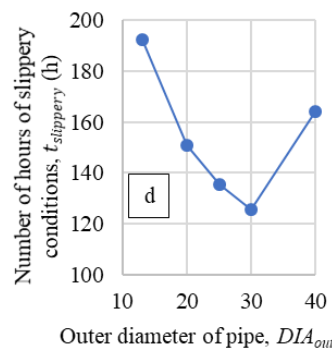

(mm)

Figure 6. The effects of pipe diameter on anti-icing operation (a) the annual required energy, (b) the average outlet temperature of fluid, $(c)$ the thermal resistances $(d)$ the remaining number of hours of the slippery conditions. 


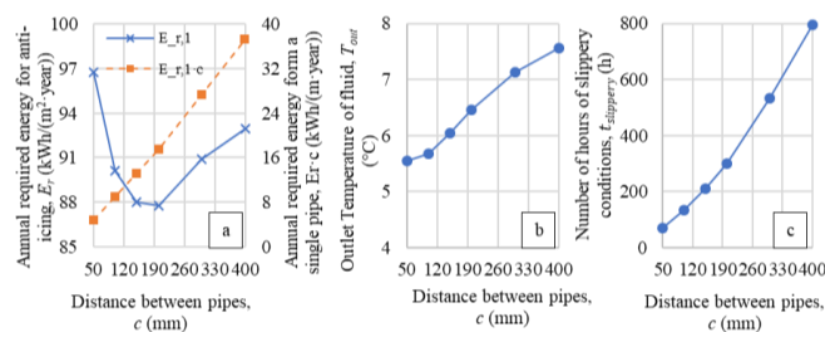

Figure 7. The effects of distances between pipes on antiicing operation (a) the annual required energy, (b) the average outlet temperature of fluid, (c) the remaining number of hours of the slippery conditions.

\section{Embedded depth of pipe}

As the embedded depth increases, the risk of reflective cracking in the asphalt pavement decreases (Dehdezi, 2012). Furthermore, installing pipes at further depth can reduce the risk of damage to the pipe networking during the rehabilitation of the road. In this study, in order to reduce the risk of structural failure in the pipes and the asphalt pavement, the pipes are located in the second and third layers. Five different embedded depth (from the centre of the pipe to the road surface) are investigated. The depths are: $60 \mathrm{~mm}, 80 \mathrm{~mm}, 100 \mathrm{~mm}, 120 \mathrm{~mm}$ and $150 \mathrm{~mm}$. The annual required energy, the average outlet temperature and the remaining number of hours of the slippery conditions are shown in Figure 8.

As illustrated in Figure 8 (a), by increasing the depth of the embedded pipes, $D(\mathrm{~mm})$ from $60 \mathrm{~mm}$ to $150 \mathrm{~mm}$, the value of $E_{r}$ increases from $86.8 \mathrm{kWh} /\left(\mathrm{m}^{2}\right.$. year) to 103.9 $\mathrm{kWh} /\left(\mathrm{m}^{2} \cdot\right.$ year $)$. The same trend is obtained for both $T_{\text {out }}$ and $t_{\text {slippery }}$ versus $D$, see Figures 8 (b) and (c). By changing the value of $D$ from $60 \mathrm{~mm}$ to $150 \mathrm{~mm}$, the value of $T_{\text {out }}$ increases from $4.5^{\circ} \mathrm{C}$ to $7.4{ }^{\circ} \mathrm{C}$. This change leads to 106 hours more slippery conditions. Installing the pipes at a deeper depth results in an increase in the thermal resistance between the pipe and road surface, see Equation 8. The increase in the thermal resistance will result in a colder surface and accordingly a higher risk for the slippery conditions on the road surface.
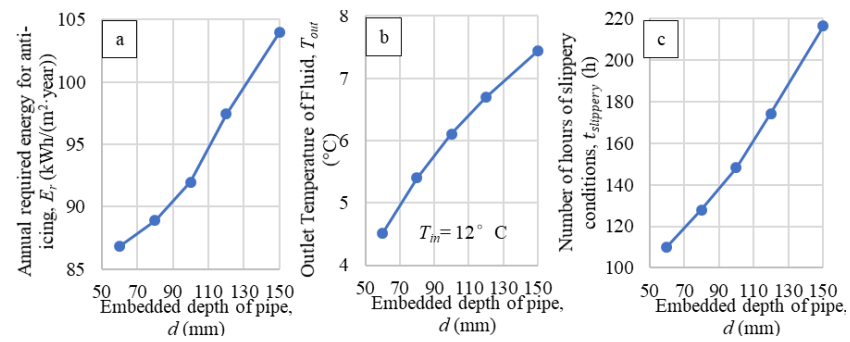

Figure 8. The effects of embedded depth of pipes on antiicing operation (a) the annual required energy, $(b)$ the average outlet temperature of fluid, (c) the remaining number of hours of the slippery conditions.

\section{Discussion and Conclusion}

It was found from this study that:

- When Reynolds number, Re (-), is equal to or below 2300, the fluid flow rate showed an significant effect on the anti-icing operation of the HHP system. Increasing the fluid flow rate from 1 1/min, where Re
$=368$, to $81 / \mathrm{min}$, where $\mathrm{Re}=2941$, resulted in approximately an $80 \%$ decrease in the number of hours of the slippery conditions on the road surface. For the fluid flow rate above $81 / \mathrm{min}$, where the value of $\operatorname{Re}>2300$, the number of hours of the slippery conditions reduced down, e.g. increasing the fluid flow rate from $81 / \mathrm{min}$ to $50 \mathrm{l} / \mathrm{min}$ led to approximately a $35 \%$ decrease in the number of hours of the slippery conditions on the road surface.

- An increase in the inlet fluid temperature resulted in a decrease in the number of hour of the slippery conditions. Increasing the inlet fluid temperature from $4{ }^{\circ} \mathrm{C}$ to $20{ }^{\circ} \mathrm{C}$ led to approximately a $65 \%$ decrease in the number of hours of the slippery conditions on the road surface.

- Considering a constant fluid flow rate of $81 / \mathrm{min}$ and increasing the outer diameter of pipe (the thickness of the embedded pipe was $2.3 \mathrm{~mm}$ constant) led to a decrease in the value of Re, affecting the remaining slippery condition. For the outer diameter equal to or smaller than $30 \mathrm{~mm}$, the value of Re was above 2300 . However, the value changed to 1695 where the outer diameter was $40 \mathrm{~mm}$, resulting in approximately 10 times increase in the surface heat transfer resistance at the inner pipe surface, $R_{P W S}(\mathrm{~m} \cdot \mathrm{K} / \mathrm{W})$. An increase in the value of $R_{P W S}$ led to an increase in the total resistance between the pipe and the road surface which in turn caused the number of hours of the slippery conditions, $t_{\text {slippery }}(\mathrm{h})$ to increase. By increasing the outer diameter of the pipe from $13 \mathrm{~mm}$ to $30 \mathrm{~mm}$, the value of $t_{\text {slippery }}$ decreased about $35 \%$. However, changing the outer diameter from $30 \mathrm{~mm}$ to $40 \mathrm{~mm}$ led to approximately a $30 \%$ increase in the number of hours of the slippery conditions on the road surface.

- The distance between the pipes played a significant role in mitigation of the slippery condition. Decreasing the distance between the pipe led to a decrease in the number of hours of the slippery condition. Changing the distance from $400 \mathrm{~mm}$ to 50 $\mathrm{mm}$ resulted in a $90 \%$ decrease in the number of hours of the slippery conditions on the road surface.

- Embedding the pipe in a shallower depth results in an increase in the conductive heat flux, transferring from the embedded pipes to the road surface. Reducing the embedded depth from $60 \mathrm{~mm}$ to $150 \mathrm{~mm}$ resulted in approximately a $50 \%$ decrease in the number of hours of the slippery conditions on the road surface.

- Among all parameters, investigated in this study, the distance between the pipes had the most significant effect on the reduction of the slippery conditions on the road surface. The next most important parameters were: the fluid flow rate, the inlet temperature of fluid, the embedded depth of the pipe and the pipe diameter.

- Comparing the results obtained from the 3D numerical model in this study and 2D models done by authors (Mirzanamadi et al., 2018) showed that increasing the pipe diameter led to a $45 \%$ decrease in the number of hours of the slippery condition using 
the $2 \mathrm{D}$ model and a $35 \%$ decrease in that using the $3 \mathrm{D}$ model. The difference between the $2 \mathrm{D}$ and $3 \mathrm{D}$ models can be explained by the variation of fluid flow rate and velocity of fluid through the pipe. In the $2 \mathrm{D}$ model, it was assumed that the velocity of fluid remains constant for all pipe with different diameters, i.e. by changing the pipe diameter, the fluid flow rate changes directly proportional to the square of the pipe diameters. However, in the 3D model, the variation of pipe diameter and the fluid flow rate were examined separately from each other i.e. it was assumed that only one of these two parameters were varied.

In this study, the effects of different parameters related to the HHP system were examined. However, the investigation was done individually for each parameter. In future work, it is necessary to find out the combined effect of the parameters on the efficiency of the HHP system, e.g. the influence of enhancing the thermal conductivity of road layers and reducing the fluid temperature on the efficiency of the HHP system. Monto Carlo method can be used in future to examine the combined parametric study of the HHP system on the anti-icing operation.

Furthermore, in this study, a hybrid 3D numerical simulation model of the HHP system is made in COMSOL Multiphysics 5.2. In future, there is a potential to simulate the HHP system coupled to the seasonal thermal energy storages and heat pumps using the available building energy simulation platforms such as "BRIDGESIM" build on TRNSYS (Pahud, 2008) and "Geothermal smart bridge" build on HVACSIM+ (Liu, 2005).

\section{Acknowledgement}

The work was supported by the Norwegian Public Road Administration and Chalmers University of Technology.

\section{References}

Abbasi, M. (2013). Master Thesis: Non-skid Winter Road, Investigation of Deicing System by Considering Different Road Profiles. Chalmers University of Technology. Gothenburg (Sweden).

Bobes-Jesus, V., Pascual-Muñoz, P., Castro-Fresno, D and J, Rodriguez-Hernandez (2013). Asphalt solar collectors: a literature review. Applied Energy 102, 962-970.

Bohne, D., Fischer, S. and E, Obermeier (1984). Thermal conductivity, density, viscosity, and prandtl-numbers of ethylene glycol-water mixtures. Ber. Bunsenges. Phys. Chem 88(8), 739-742.

Dehdezi, P. K. (2012). PhD Thesis: Enhancing Pavements for Thermal Applications, Department of civil engineering at the University of Nottingham. Nottingham (UK).

Hagentoft, C.E. (2001). Introduction to Building Physics. Studentlitteratur. Lund (Sweden).

Hagentoft, C.E., \& Roots, P. (2016). Design rules for floor heating system using new analytical formulas. Proceedings from CESBP Central European Symposium on Building Physics and BauSIM 2016. Dresden (Germany), 14-16 September 2016.

Johnsson, J. (2017). Licentiate Thesis: Winter Road Maintenance Using Renewable Thermal Energy. Chalmers University of Technology. Gothenburg (Sweden).

Liu, X. (2005). PhD Thesis: Development and Experimental Validation of Simulation of Hydronic Snow Melting Systems for Bridges. Oklahoma State University. Oklahoma (USA).

Meteotest (2010). Meteonorm: Global Meteorological Database. Handbook part II: Theory, version 6.1. Meteotest. Bern (Switzerland).

Mirzanamadi, R., Hagentoft, C.E., Johansson, P and J, Johnsson (2018). Anti-icing of road surfaces using hydronic heating pavement with low temperature. Cold Regions Science and Technology 145, 106-118.

Mirzanamadi, R., Hagentoft, C.E. and P, Johansson (2018). Numerical investigation of harvesting solar energy and anti-Icing road surfaces using a hydronic heating pavement and borehole thermal energy storage. Energies 11(12), 1-23.

Modin, B. O. (2015). Summary of Properties for Different Pipe Types. Energy analys jämtland. Östersund (Sweden).

Ou, T., Hu, Y., Gustavsson, T and J, Bogren (2018). On the relationship between the risk of hoar frost on roads and a changing climate in Sweden. International Journal of Climatology 39(5), 2601-2611.

Pahud, D. (2008). Simulation Tool for the System Design of Bridge Heating for Ice Prevention with Solar Heat Stored in a Seasonal Ground Duct Store. Swiss Federal Institue of Energy. Bern (Switzerland).

Pan, P., Wu, S., Xiao, Y and L, Gang (2015). A review on hydronic asphalt pavement for energy harvesting and snow melting. Renewable and Sustainable Energy Reviews 48, 624-634.

The Engineering ToolBox (2001). Maximum Flow Velocities in Water Systems. Available at: http://www.engineeringtoolbox.com/flow-velocitywater-pipes-d_385.html (Accessed: 17 July 2017). 